\title{
ANÁLISIS DE LA SENTENCIA C- 241 DE 2010 Y SU RELACIÓN CON LOS DERECHOS FUNDAMENTALES AL DEBIDO PROCESO Y A LA VIVIENDA DIGNA ${ }^{1}$
}

\section{Analysis to Case C-241 of 2010 and its Relation to the Fundamental Rights to Due Process and to Decent Housing ${ }^{1}$}

Diana Beltrán Barcos ${ }^{2}$

Fecha de Recepción: Noviembre 3 de 2014

Fecha de Aceptación: Noviembre 10 de 2014

SUMARIO: 1. Introducción; 2. Desarrollo, 2.1 Análisis estático de la sentencia c-241 de 2010, 2. 2 El debido proceso como derecho fundamental: construcciones desde la jurisprudencia y la doctrina, $2.3 \mathrm{EI}$ derecho fundamental a la vivienda digna: Sentencias colindantes; 3. Conclusiones;

4. Referencias bibliográficas.

${ }^{1}$ El presente artículo de investigación, es resultado de los estudios adelantados al interior de la Especialización en Derecho Administrativo de la Universidad Libre Sede Cartagena, como requisito académico para optar al título.

${ }^{2}$ Abogada y Especialista en Derecho de Familia de la Universidad de Cartagena. Especialista en Derecho Administrativo de la Universidad Libre, Sede Cartagena. Defensora de Familia I.C.B.F. 


\section{COMO SE CITA ESTE ARTÍCULO (APA 6)}

Beltrán Barcos, Diana. (2014) Análisis a la sentencia c-241 de 2010 y su relación con los derechos fundamentales al debido proceso y a la vivienda digna. (Y. Carrillo De la rosa, Ed.) Revista Jurídica Mario Alario D'Filippo, VII (13), pág. 10-17

\section{RESUMEN}

El presente artículo presenta la problemática de considerar si el Artículo 15 de la Ley 57 de 1905, viola los derechos fundamentales al debido proceso y a la vivienda digna, de las personas que ocupan predios rurales, sin justo título, y que se ven obligadas a ocupar dichos terrenos o predios por la necesidad de no tener una vivienda digna o lugar de residencia necesario para suplir sus intereses personales y familiares. Para esto, analizaremos la Sentencia C-241 de 2010, cuyo tenor nos permitirá identificar, a través de un análisis estático, los hechos relevantes de la jurisprudencia, el problema jurídico planteado, las consideraciones de la Corte Constitucional, y la decisión que finalmente adopte, con relación a la protección o vulneración de los derechos fundamentales al debido proceso y a la vivienda digna.

\section{PALABRAS CLAVE}

Derechos Fundamentales, debido proceso, vivienda digna, jurisprudencia constitucional.

\section{ABSTRACT}

This article presents the problem of considering whether Article 15 of Law 57 of 1905, violates fundamental due process and fair housing, people occupying rural land without just title, and who are forced to occupy rights such land or premises by the need not to have a decent home or place of residence needed to meet their personal and family interests. For this, we will analyze the Judgment C-241 of 2010, which states allow us to identify, through a static analysis, the relevant facts of the case, the proposed legal problem, considerations of the Constitutional Court, and the decision finally adopted in relation to the protection or violation of fundamental rights to due process and adequate housing.

\section{KEYWORDS}

Fundamental rights, due process, decent housing, the constitutional court. 


\section{INTRODUCCIÓN}

La sentencia C-241 de 2010, expone la controversia jurídica de determinar si en las actuaciones policivas de lanzamiento, por ocupación de hecho de predios rurales, es garantizado el derecho de defensa de quienes ocupan los predios sin la presentación del justo título. El examen de constitucionalidad de la disposición legal se examina, en el Artículo 15 de la Ley 57 de 1905.

En una primera media se observa la posible vulneración del derecho fundamental al debido proceso; que de conformidad a los argumentos del actor en la demanda, se presentaría una lesión no solo al núcleo esencial del derecho constitucional al debido proceso, sino a los demás principios constitucionales que integran la unidad normativa de la disposición en mención, como son las demás garantías que se desprenden del Artículo 29 Constitucional, a saber, el derecho de defensa, el juez natural, el derecho de ejercicio de contradicción, entre otros. Resultando así, un desconocimiento de las garantías constitucionales, que equilibrarían las cargas a un posible desconocimiento de los intereses y derechos de la parte menos favorecida en la actuación policiva, como lo es aquella persona que ostente las calidades de un tenedor del bien sin justo título, u otro que observe la legalidad de su ocupación.

Finalmente como segunda medida, se establece la posibilidad, que no solo con la actuación policiva, tendiente a la recuperación de la tenencia y posterior goce del bien o predio rural, de aquella persona que tenga el pleno reconocimiento de sus derechos reales sobre el mismo, se dé la configuración, a la posible vulneración al derecho fundamental a la vivienda digna, ya que si es lanzada la persona que ocupaba el predio, y este se establecía como su lugar de habitación, dicha actuación podría establecer un desconocimiento al derecho a disfrutar de una vivienda digna.

En este orden de ideas, en el presente artículo de reflexión, mostraremos una análisis de las discusiones centrales que aquí hemos enunciado, y si estas guardan estrecha relación, a la protección o vulneración de los derechos constitucionales fundamentales al debido proceso y a la vivienda digna. Además apoyándonos en la jurisprudencia en estudio, la C-241 de 2010, en su análisis estático identificaremos las razones teóricas y argumentativas que jueguen en la determinación de una posible situación, que identifique, las dos posibilidades que arrojaría una conclusión final, si se presentaría una vulneración o desconocimiento a los derechos fundamentales al debido proceso y a la vivienda digna, con la realización o no de la actuación policiva de restablecimiento del inmueble ocupado, por una persona que no posea justo título o medie contrato alguno que justifique la ocupación.

\section{DESARROLLO}

\subsection{ANÁLISIS ESTÁTICO DE LA SENTENCIA C-241 DE 2010}

En este análisis de la Sentencia C-241 de 2010, contrastaremos la norma demandada en acción pública de inconstitucionalidad, el problema jurídico relevante, las consideraciones de la Corte Constitucional y finalmente la decisión adoptada por este alto tribunal, con relación al objeto de estudio del presente artículo de reflexión. 
Así, la norma demanda es la siguiente:

“LEY 0057 DE 1905

(Abril 29)

"Sobre reformas judiciales".

LA ASAMBLEA NACIONAL CONSTITUYENTE Y LEGISLATIVA,

DECRETA:

ARTíCULO 15.- Cuando alguna finca ha sido ocupada de hecho sin que medie contrato de arrendamiento ni consentimiento del arrendador, el jefe de policía ante quien se presente la queja se trasladará al lugar en que esté situada la finca dentro de las cuarenta y ocho horas después de la presentación del escrito de queja; y si los ocupantes no exhiben el contrato de arrendamiento, o se ocultan, procederá a verificar el lanzamiento sin dar lugar a recurso alguno ni a diligencia que pueda demorar la desocupación de la finca.

PÁRAGRAFO.-El jefe de policía moroso en el cumplimiento del deber que le impone el inciso anterior, será responsable en la misma forma y términos de que trata el Artículo 12".

Una vez observada la norma demandada entraremos a establecer el problema jurídico que se presenta en la Sentencia C-241 DE 2010:

El actor en la demanda, esgrime que el Artículo 15 de la Ley 57 de 1905, es violatorio del orden constitucional, concretamente al Artículo 29 de la Carta Política, el cual se refiere al debido proceso. Puntualmente se fundamenta la acción en considerar que el poder de la actuación policiva, tendiente a restablecer un predio rural, ocupado de hecho, sin que medie contrato de arrendamiento o consentimiento del arrendador, podrá el jefe de policía realizar la diligencia de lanzamiento. Los cargos que se presentan se dirigen exclusivamente, a orientar la acción, aun desconocimiento de los principios que integran el debido proceso como tal, a saber, el derecho de defensa, el derecho de contradicción, el de libertad probatoria.

\section{Las consideraciones de la Corte Constitucional rezan al respecto:}

En un primer aspecto la Corte reflexiona, entorno a los límites y alcances del poder de policía, sobre esto ha manifestado el alto tribunal, que el poder de policía, siempre debe estar orientado al cumplimiento del principio de legalidad, y su actividad y despliegue debe dirigirse a la preservación y restablecimiento del orden público, puntualmente la Corte Constitucional plantea su dicho al respecto:

La norma que se estudia en sede constitucional corresponde a aquellas que se expiden en ejercicio de la facultad legislativa como fuente del poder de policía y que tienen por finalidad mantener el orden público y garantizar la preservación de la seguridad, salubridad y tranquilidad públicas, como condición para el libre ejercicio de las libertades democráticas. En el caso particular de la norma demandada, el poder de 
policía se concreta en defensa del derecho a la propiedad y sus derechos conexos a la posesión y la tenencia, en punto a protegerlos de perturbaciones individuales y colectivas de manera provisional y hasta tanto la titularidad de los derechos reales en controversia sean definidos por la autoridad judicial competente. Es así como, en aras de enmarcar conceptualmente el contexto de discusión que la presente acción supone, la Sala realizará unas breves referencias al Poder de Policía. (Corte Constitucional, Sentencia C-241 de 2010. MP. Juan Carlos Henao Pérez)

En un segundo aspecto, la Corte estableció, que en el procedimiento que se regula, con el Artículo 15 de la Ley 57 de 1905, se establecieron todos los mecanismos garantizadores de los derechos de defensa y contradicción, integrantes del núcleo común del derecho fundamental al debido proceso, la Corte proyecto así su consideración:

Estas acciones policivas se crean con el fin de otorgar protección provisional tanto a bienes inmuebles rurales como urbanos, de forma que se resuelvan transitoriamente los conflictos surgidos entre particulares, hasta tanto la justicia ordinaria decida de fondo sobre los derechos en conflicto. Es ese sentido, las acciones previstas en el Código de Policía tienen un carácter instrumental con el fin de impedir vías de hecho que signifiquen perturbación, razón por la cual se otorga a la autoridad policiva la facultad de tomar medidas destinadas a preservar y restablecer la situación existente al momento de producirse la perturbación. (Corte Constitucional, Sentencia C-241 de 2010. MP. Juan Carlos Henao Pérez)

De conformidad a lo anterior la Corte Constitucional pronuncio su decisión:

PRIMERO.- Declararse INHIBIDA, por ausencia actual de objeto, para estudiar la exequibilidad del Artículo 15 de la Ley 57 de 1905.

SEGUNDO.- Exhortase al Congreso de la República para actualizar, modificar e introducir los ajustes que sean necesarios al actual Código Nacional de Policía contenido en el Decreto legislativo 1355 de 1970.

La Corte no encontró objeto, que fundamentara la presencia de un cargo real de inconstitucionalidad, por lo que declarándose inhibida no decidió de fondo sobre la petición formal de la demanda.

\subsection{EL DEBIDO PROCESO COMO DERECHO FUNDAMENTAL: CONSTRUCCIONES DESDE LA JURISPRUDENCIA Y LA DOCTRINA}

El debido proceso se instituye principalmente, como un principio constitucional. Bajo esta perspectiva, este es reconocido como derecho fundamental en la constitución política nacional. Este reconocimiento va a permitir que el derecho tenga una gran fuerza normativa en todas las actuaciones judiciales. Establecido este principio en nuestro derecho positivo por vía del Artículo 29 Constitucional, se eleva a la categoría de derecho fundamental de aplicación sin restricciones a toda actuación jurisdiccional y administrativa, no solo para la defensa, garantía y protección de los bienes jurídicos de la vida, la propiedad, la libertad y la persona, como en el derecho 
norteamericano, sino de todos demás bienes que eventualmente se encuentren en juego en una actuación procesal. (Santofimio, 2003, pp. 60-61)

Este derecho, además de ser un verdadero derecho fundamental de garantía por excelencia, se convierte en pilar fundante del estado social de derecho, en el cumplimiento del principio de legalidad de la actuación en sede judicial, porque a grandes el debido proceso, establece un sistema de sub-principios constitucionales, como el del juez natural, la doble instancia, el derecho de defensa, el derecho de contradicción, la libre valoración probatoria, entre otros. Lo que hace del derecho fundamental al debido proceso un sistema de técnicas de garantía en la preservación de la legalidad y el cumplimiento del Estado de derecho. La Corte Constitucional se ha referido sobre el debido proceso como un derecho que preserva la seguridad jurídica de los asociados en el ámbito de la actuación procesal:

El debido proceso y el acceso a la administración de justicia son derechos fundamentales que obligan a interpretar las normas procesales como instrumentos puestos al servicio del derecho sustancial y de las soluciones que permitan resolver el fondo de los asuntos sometidos a consideración de los jueces. Se impone, por lo tanto, adoptar la interpretación que tome en cuenta el espíritu y la finalidad de la norma y que sea más favorable para la efectividad del derecho fundamental. (Corte Constitucional, Sentencia T-538 de 1994)

En cuanto a la esfera de concreción, el debido proceso debe ser aplicado en toda actuación judicial y administrativa, no solo las que se hagan en función jurisdiccional, sino aquellas en cumplimiento de funciones de instrucción o investigación, en aras de fortalecer los mecanismos y vías jurídicas a la hora de establecer medidas limitantes de las libertades públicas. Nuestra constitución consagra varias reglas que tienden precisamente a garantizar el derecho de defensa de los individuos contra quienes se haya formulado acusaciones de haber infringido la ley penal o contra quienes se adelanta un proceso cualquiera para deducirle alguna clase de responsabilidad. Hacen referencia a las garantías procesales, en las cuales, nadie puede ser condenado sin haber sido oído y vencido en juicio, juicio que debe adelantarse con la plenitud de las formalidades legales por juez competente y que no se le puede obligar a declarar contra sí mismo y a sus parientes contra él, a las garantías de un proceso público y sin dilaciones, al derecho a impugnar las providencias y a no ser juzgado dos veces por el mismo hecho y a la seguridad jurídica. (Pérez, 2004, p. 307). Se direcciona así, el derecho fundamental al debido proceso, como un derecho complementario de otros derechos y principios consagrados en la constitución, sobre esto la Corte Constitucional ha dicho:

En este orden de ideas, el derecho al debido proceso hace referencia a un conjunto complejo de circunstancias, señaladas por la Constitución y la ley que protegen al ciudadano sometido a cualquier proceso, asegurándole a lo largo del mismo la posibilidad de defender sus intereses mediante el señalamiento expreso de los requisitos y obligaciones que debe cumplir y de los recursos con los que cuenta para impugnar las decisiones de la autoridad. Pero también la existencia de un principio de esta naturaleza refiere la necesidad de dar cumplimiento a una secuencia de actos, relacionados entre sí de manera directa o indirecta, que persiguen un objetivo adicional: la racionalización del ejercicio del poder de tal manera que se reconozca en la ley, y no en la voluntad, en la fuerza o en la arbitrariedad, la forma de resolución de las contenciones de derecho. (Corte Constitucional. Sentencia T-945 de 2001, M.P: Manuel José Cepeda Espinosa) 


\subsection{EL DERECHO FUNDAMENTAL A LA VIVIENDA DIGNA: SENTENCIAS COLINDANTES}

El derecho fundamental a la vivienda digna, se estructura como un derecho de protección, en la esfera de los intereses ciudadanos, en la satisfacción de sus condiciones básicas para una vida digna. Es así, que el derecho a la vivienda digna como derecho fundamental, va a indicar que dentro de unas condiciones de satisfacción, el derecho a tener una morada que cumpla con las condiciones necesarias para un desarrollo de las actividades humanas, va a ser primordial en el atendido de la cláusula del Estado social de derecho colombiano.

Es importante indicar que el derecho fundamental a la vivienda digna tiene alto contenido prestacional, y su reconocimiento va a estar ligado, a que este encuentre el factor de conexidad para su protección, como lo ha señalado la Corte Constitucional a través de su jurisprudencia:

El derecho a la vivienda digna adquiere rango fundamental, cuando opera el factor de conexidad con otro derecho fundamental, o cuando puede evidenciarse una afectación del mínimo vital, especialmente en personas que se encuentran en una situación de debilidad manifiesta, ya que, como lo ha reiterado esta Corporación, el derecho a la vivienda adquiere importancia en la realización de la dignidad del ser humano. Así, la prosperidad de una tutela para la protección de este derecho, dependerá de las condiciones jurídicomateriales del caso concreto en las que el juez constitucional determine si la necesidad de vivienda conlleva elementos que involucran la dignidad o la vida de quien acude a esta instancia judicial. (Corte Constitucional, Sentencia, T-1091 de 2005. M.P. Clara Inéz Vargas Hernández)

En estos términos el derecho fundamental a la vivienda digna, es expresado como mandato de optimización, es decir, su realización va a estar supeditada, a las posibilidades fácticas y a las condiciones concretas para que el derecho sea reconocido por el juez constitucional a través de una acción de tutela, esto lo que va a indicar que los derechos con alto contenido prestacional, dependerán siempre de las condiciones reales y materiales del caso concreto. Es esta misma línea, como garantía especial, que contribuye al amparo y protección, el derecho fundamental a la vivienda digna se estructura como derecho prestacional por excelencia, en los denominados, derechos económicos, sociales y culturales, a lo que la Corte Constitucional hace referencia, como derecho con alto contenido para el interés social:

La Constitución establece el "derecho a vivienda digna" como uno de los derechos sociales y económicos de los colombianos, el cual, desde luego, no puede por su propia índole ser de realización inmediata sino progresiva. Por ello, el constituyente ordena al Estado la fijación de "las condiciones necesarias para hacer efectivo este derecho", así como el promover "planes de vivienda de interés social", y "sistemas adecuados de financiación a largo plazo". Es decir, conforme a la Carta Política no puede la adquisición y la conservación de la vivienda de las familias colombianas ser considerada como un asunto ajeno a las preocupaciones del Estado, sino que, al contrario de lo que sucedía bajo la concepción individualista ya superada, las autoridades tienen por ministerio de la Constitución un mandato de carácter específico para atender de manera favorable a la necesidad de adquisición de vivienda, y facilitar su pago a largo plazo en condiciones adecuadas al fin que se persigue, aún con el establecimiento de planes específicos para los sectores menos 
pudientes de la población, asunto éste último que la propia Carta define como de "interés social". (Corte Constitucional, Sentencia C-383 de 1999. M.P. Alfredo Beltrán Sierra)

\section{CONCLUSIONES}

Es evidente que tanto el derecho fundamental al debido proceso, como el derecho fundamental a la vivienda digna, deben ser garantizados por el Estado colombiano, en aras del cumplimiento de los postulados fundamentales de la cláusula social.

Puntualmente, al revisar la Sentencia C-241 de 2010, en el examen de constitucionalidad de estos dos derechos en el marco superior de protección, contrastados en el Artículo 15 de la Ley 57 de 1905, que dispone, el procedimiento policivo de lanzamiento por ocupación de hecho de predios rurales, no encontramos vulneración alguna de las garantías constitucionales al debido proceso y a la vivienda digna. Una vez que no se vulneran estos derechos, pues la actividad desplegada por la autoridad de policía, para preservar los derechos reales de aquellas personas que los ocupen sin justificación alguna, es el reconocimiento de la legalidad y de las plenas facultades en un Estado de derecho, por lo que consideramos que no existieron méritos para declarar la inconstitucionalidad de las disposiciones legales.

\section{REFERENCIAS BIBLIOGRÁFICAS}

SANTOFIMIO, J. (2003) "Tratado de derecho administrativo". Tomo II. Tercera edición, Universidad Externado, Bogotá, Colombia.

PÉREZ, J. (2004) “Derecho constitucional colombiano”. Séptima edición. Editorial Temis, Bogotá, Colombia.

\section{SENTENCIAS}

CORTE CONSTITUCIONAL, Sentencia C-241 de 2010. MP. Juan Carlos Henao Pérez.

CORTE CONSTITUCIONAL. Sentencia T-945 de 2001, M.P. Manuel José Cepeda Espinosa.

CORTE CONSTITUCIONAL, Sentencia, T-1091 de 2005. M.P. Clara Inés Vargas Hernández.

CORTE CONSTITUCIONAL, Sentencia C-383 de 1999. M.P. Alfredo Beltrán Sierra. 